Original Research Paper

\title{
Investigating the Efficacy of a Bio-Based Modifier to Improve the Rheological Properties of Recycled Asphalt Shingles
}

\author{
Mohammed Jawad, Elham H. Fini and Taher M. Abu-Lebdeh \\ Department of Civil, Architectural and Environmental Engineering, \\ North Carolina A\&T State University, Greensboro, NC 27411, USA
}

rticle history

Received: 19-02-2017

Revised: 27-02-2017

Accepted: 10-03-2017

Corresponding Author: Taher M. Abu-Lebdeh

Department of Civil,

Architectural and

Environmental Engineering,

North Carolina A\&T State

University, Greensboro, NC

27411, USA

Email: taher@ncat.edu

\begin{abstract}
This study investigates the use of Bio-Binder, derived from swine manure, as an additive to improve rheological properties of bitumen extracted from recycled asphalt shingles. Test results show that adding Bio-Binder to Recycled Asphalt Shingles (RAS) leads to reduced viscosity, modulus shear complex $\mathrm{G}^{*}$, relaxation time RT and segregation. Results illustrated that the derived Bio-Binder additive can remove the negative impact of oxidation and rejuvenate bitumen extracted from recycled asphalt shingles.
\end{abstract}

Keywords: Recycled Asphalt Shingles RAS, Bio-RAS, Bio-Modified Asphalt, Bio-Binder

\section{Introduction}

The main point in this study is the quality and price of asphalt concrete. There is a need to find the best way to reduce the price of asphalt concrete without negatively affecting the quality of pavement construction. Per previous studies, there are four cost categories for asphalt production: Materials, Plant production, Trucking and Lay down. Among them, Materials is the most expensive production cost category, constituting $70 \%$ of the cost to produce hot mix asphalt and bitumen. Therefore, it is very important to reduce the cost of bitumen to reduce the total cost of asphalt concrete pavement, to continue the construction of new roads and required road maintenance.

RAS is a process of reusing the extracted asphalt shingles from roof tear-offs and/or manufactured waste asphalt shingles in other products such as asphalt pavement. This, in turn ensures that the waste materials do not end up in the landfill. The benefits of Recycled Asphalt Shingles (RAS) are that they are economically viable, convenient where available and save valuable resources from being sent to a landfill.

\section{Regulation of RAS}

Regulations regarding the use of recycled asphalt shingles vary from state to another; some states permit up to $5 \%$ recycled asphalt shingles in asphalt concrete, while others allow up to $15 \%$. This creates a patchwork regulatory environment that poses challenges for the construction industry. On the other hand, several states have promoted laboratory as well as field studies to investigate the feasibility of using RAS in asphalt pavement. States such as North Carolina, Texas, Ohio, Georgia and Minnesota have conducted several laboratory studies investigating the feasibility of using RAS in HMA pavement. Additionally, Field projects have been performed in which segments of highways have been paved with modified HMA pavement.

\section{Relationship between RAS, Bitumen and Aggregate}

The U.S currently produces about 1.8 million metric tons of aggregate each year. Production is projected to increase to 2.3 MT by the year 2020. Aggregate materials and asphalt binder (bitumen) are non-renewable; therefore, recycled asphalt shingles could provide relief for road builders. There are several grades of RAS as shown in Fig. 1. Typically, Asphalt shingles contain 20 to $30 \%$ Asphalt Cement (AC) and up to $38 \%$ aggregate, both components are common highway materials. Using recycled asphalt shingles as a raw material creates new jobs and reduces the costs, energy, labour and environmental impact of extracting, transporting and processing raw materials. Building roads that use recycled asphalt shingles in the pavement mix makes sense. In fact, asphalt pavement can be considered as one of the most recycled materials because more than $80 \%$ of all asphalt is recycled back to pave highways and roads. 


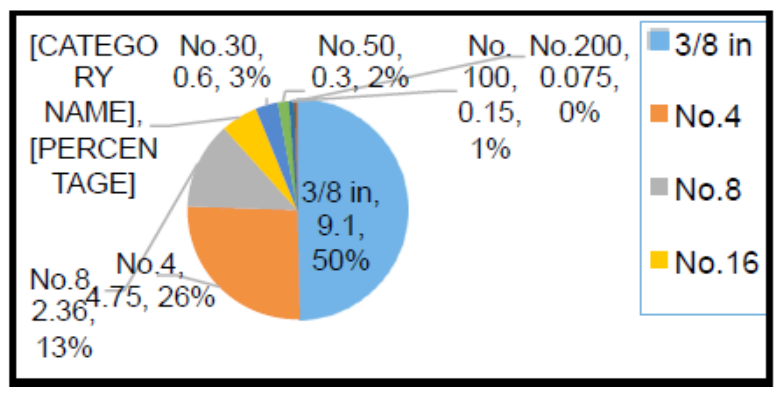

Fig 1. Recycled asphalt shingles gradation

Several states such as North Carolina, Minnesota and Pennsylvania have carried out several filed projects where segments of trail ways or highways were paved with pavements contained recycled asphalt shingles. The use of RAS resulted in reduction in the overall cost of the project due to the use of less amount of the increasingly expensive virgin binder. Typically, manufactured asphalt shingles contain about 40\% asphalt, thus using RAS in pavements offer an economical alternative to regular pavements normally used in paving highway projects.

In 2005, AASHTO adopted standard specifications for the use of recycled asphalt shingles in HMA pavements. These national specifications and guidelines enable HMA producers to produce mixtures that contain RAS and satisfy their state and local specifications. The specifications allow the use of both tear-off asphalt shingles and manufactures waste asphalt shingles (Nam et al., 2014). In 2006, AASHTO adopted a recommended practice, PP 53, to supplement the standard specification and then updated it in 2009. These provide significant aid and encouragement for utilizing RAS in HMA.

A study by Oldham et al. $(2014 ; 2015)$ showed that adding bio-binder to bitumen derived from shingles is beneficial to reduce overall viscosity while also improving the low-temperature properties of biobitumen from shingles. This would alleviate bio-bitumen shingles' stiffening effect, enhancing bio-bitumen pump ability and reducing both mixing and compaction temperatures of bio-shingle modified pavement.

A study by Elseifi et al. (2012) proved that incorporating RAS in binders improved its high temperature grade, but increased rutting in the pavement at relatively high temperature and increased fatigue cracking at low temperature. Moreover, the optimum shingle content in the asphalt concrete is no more than $20 \%$. This percentage of scrap shingle would improve the binder's high-temperature grade without affecting the lower end grade. Increasing the percentage of scrap shingle to more than $20 \%$ leads to an increase in segregation in the asphalt concrete shingle (Elseifi et al., 2012). In addition, results of high pressure gel permeation chromatography indicated that the high content of high molecular weight in the RAS's binder compared to the virgin binders negatively affect the mixing process of the RAS binder. Further, Oldham et al. (2014) demonstrated that adding shingles to virgin asphalt binder improved the upper temperature grade, but reduced the low end grade

\section{Materials and Methods}

\section{Asphalt Binder}

The asphalt binder used in this study is PG 64-22 asphalt. The binder sustains conditions of maximum pavement temperature of $64^{\circ} \mathrm{C}$ and minimum pavement temperature of $-22^{\circ} \mathrm{C}$. The neat binder used in this project was provided by Sharpe Brothers Company, Greensboro, North Carolina.

Recycled scrap shingles: The Tear-Off scrap shingles material used in the present study was provided by S.T. Wooten's Quality Control Lab, Sanford, NC. The initial particle size of the asphalt shingles was in the range of 12.5 to $19.00 \mathrm{~mm}$. The shingles were further processed by dry-grinding the shingles for $30 \mathrm{~min}$, using a new technique developed by Oldham et al. (2015). The final particle size was reduced to $0.085 \mathrm{~mm}$ ensuring adequate interaction between RAS particles and the binder and reducing particle settling. To prepare test specimens with the highest homogeneity between shingles and binder, the wet processing was used.

To prepare specimens, graded $90 \%$ RAS was blended with $10 \%$ of PG 64-22 binder. Mixtures were prepared at $180^{\circ} \mathrm{C}$ using mechanical shear mixer rotating at $750 \mathrm{rpm}$ for $1 \mathrm{~h}$. Further, to prevent segregation and to ensure homogeneity, samples were re-blended at $180^{\circ} \mathrm{C}$ for $5 \mathrm{~min}$ at $750 \mathrm{rpm}$.

\section{Bio-Binder}

The Bio-Binder developed by Fini et al. (2011) was used herein. This Bio-Binder was produced at NC A\&T swine research facility.

\section{Bio-Modified Shingles}

The Bitumen derived from Recycled Asphalt Shingles (RAS) was blended with PG $64-22$ at $180^{\circ} \mathrm{C}$ and $750 \mathrm{rpm}$ for $60 \mathrm{~min}$; the wet process was used to prepare these samples. Then the sample was heated at $135^{\circ} \mathrm{C}$ for $60 \mathrm{~min}$ to give the bitumen derived from recycled shingles enough time to stabilize at this temperature. After that, the sample was mixed with BioBinder at $135^{\circ} \mathrm{C}$ using $750 \mathrm{rpm}$ for $60 \mathrm{~min}$. The mixing temperature was reduced from 180 to $135^{\circ} \mathrm{C}$ because of Bio-Binder enhancing the workability of the mixture and to protect Bio-Binder from burning. When the mixing was finished, the RV test, DSR Test and CTT were used to evaluate the Bio- Modified Shingles. 


\section{Testing Methods}

\section{Rotational Viscometer Test (RV)}

The Rotational Viscometer (RV) is an instrument used to determine the viscosity of binders in high temperature range. The RV measures torque and converts it automatically to viscosity, shear stress and shear rate. The Brookfield Viscometer RV-DVIII Ultra was used in this study, following AASHTO T316 or ASTM D4402 specifications (Pavement interactive). In this study, the cross spindle V-73 was used to measure viscosity of both RAS and RAS modified, to make sure the viscosity measurement of specimens is accurate due to the stiffness of recycled asphalt shingles used in this study. The specimens are RAS, Bio-RAS and asphalt PG 64-22. Samples preparation starts by pouring $10.5 \mathrm{~g}$ of specimen into an aluminum chamber and allowing it to cool to room temperature. Then a chamber and cross spindle V-73 are placed into an oven for $30 \mathrm{~min}$ to preheat the samples to the initial test temperature: For RAS, it is $180^{\circ} \mathrm{C}$, for RAS + Bio-Binder and neat binder, the temperature is $105^{\circ} \mathrm{C}$. During this time, the Thermoset of the RV is preheating to the same temperature required. Once the chamber and spindle are placed into the Thermoset of the RV, the entire system is allowed an additional $20 \mathrm{~min}$ to reach thermal equilibrium. Twenty-minute intervals are used for each additional temperature for testing. After $20 \mathrm{~min}$, the rotation of the spindle begins and a viscosity reading is taken every $3 \mathrm{~min}$. This is performed 3 times at the same $\mathrm{rpm}$ and the average of three readings is taken to be the true value. In addition, $20 \mathrm{~min}$ intervals are used for each additional temperature for testing. For one temperature, the maximum acceptable time is $1.5 \mathrm{~h}$; for two temperatures, $2.5 \mathrm{~h}$ (AASHTO T 316, 2012).

\section{Dynamic Shear Rheometer (DSR)}

Neat binder is a viscoelastic material; therefore, it works as an elastic solid material at low temperature and as a viscous liquid at high temperature. The DSR can evaluate both the elasticity and viscosity behavior of the PG 64-22 binder, Recycled Asphalt Shingles (RAS) and Bitumen Modified Shingles (Bio-RAS) at medium and high temperature by tracking the shear stress and shear strain.

Dynamic shear rheometer typically measures the complex shear modulus $\left(G^{*}\right)$ as well as the phase angle $(\delta)$ (ASTM D7552-09, 2014). The complex shear modulus may be defined as the ratio of total shear stress $\left(\eta_{\max }-\eta_{\min }\right)$ to the total shear strain to represent the asphalt's dynamic shear resistance to deformation. The phase angle is also measured because asphalt is not a purely elastic material. The phase angle is defined as the time between the applied shear stress and the resulting shear strain. It may be taken as zero for purely elastic materials and $90^{\circ} \mathrm{C}$ for purely viscous materials. The complex shear modulus $\left(G^{*}\right)$ has two components: (1) Elastic component $\left(G^{\prime}\right)$ and (2) viscous component $\left(G^{\prime}\right)$. Fatigue cracking resistance and rutting resistance may be determined from these properties. Fini et al. (2011) concluded that asphalt binders with the highest $G^{*} / \sin \delta$ value are normally best binders to resist rutting, Therefore, the elasticity component of the complex shear modulus should be as large as possible, because the higher $G^{*}$ value, the lower phase angle and thus the stiffer the asphalt binder as shown in the following relation:

$$
\operatorname{Sin}(\delta)=\text { Viscous } G^{\prime \prime} / \text { Complex Shear Modulus } G^{*}
$$

\section{Cigar Tube Test}

Cigar Tube Test (CTT) was utilized to evaluate the compatibility and stability of the prepared samples. Evaluation was conducted by observing any changes in properties of the samples extracted from the top and bottom of the sample. Changes as function of time were used to determine the potential for degradation in the field. CTT test was performed to determine whether the asphalt modifier may separate from the asphalt binder during static heated storage. Agitation, stirring, or may be re-formulating the binder is considered when the modified asphalt binder shows signs of separations during storage. It should be noted that testing was conducted following ASTM D7173-14. Once blending is completed, $50 \pm 0.5 \mathrm{~g}$ of hot asphalt binder is poured into aluminium tube, the open end of the tube was sealed and the tube was stored in an oven at $163 \pm 5^{\circ} \mathrm{C}$ and allowed to condition for $48 \pm 1 \mathrm{~h}$ (Soleimanbeigi et al., 2013). Once the conditioning is completed, the tube assembly was immediately placed in a freezer allowing the sample to freeze for at least $4 \mathrm{~h}$. Then, the sample was removed from the freezer and cut into three equal portions. Discarding the middle portion, the top and bottom portions were separately placed in $3 \mathrm{oz}$ tins and heated to fluid state in which the asphalt binder can flow from the tube. Then, the two asphalt binder samples were stirred thoroughly before conducting the comparative DSR testing to determine the difference in hightemperature grading of the top and bottom portions (Soleimanbeigi et al., 2013). Results in terms of percent separate were used to assess the viscosity, the complex shear modulus and level of separation.

\section{Results}

This research project studied the effect of Bio-Binder (BB) on the viscosity, complex shear modulus, relaxation time and segregation of modified asphalt that has a high percentage of bitumen extracted from recycled asphalt shingles. 


\section{Influence of Bio-Binder on the Viscosity of $90 \%$} $R A S+0 \% B B$

The high temperature viscosity of neat binder, $90 \%$ RAS and modified asphalt shingles (90\% RAS $+30 \%$ BB) was determined by the rotational viscosity test. Figure 2 shows the difference between the viscosity of neat asphalt when measured using cross spindle and using cylinder spindle. As shown, the cross spindle gives viscosity value 3 times higher than the viscosity measured by using cylinder spindle. All viscosity measurements in this study were done using cross spindle, because the cross spindle is more accurate when used with stiff materials. In addition, all manufacturers prefer to use a cross spindle to measure viscosity because it has the same working principle as a binder pump

Figure 2 shows that the viscosity value of neat asphalt PG64-22 is much higher when measured using a cross spindle than when measured using a cylinder spindle. The viscosity measured using a cross spindle is higher by $64,40,42$ and $61 \%$ at $120,135,150$ and $165^{\circ} \mathrm{C}$, respectively.

Figure 3 illustrates the equations fitted to the original test data. It is not possible to run the RV test to find the viscosity of $90 \%$ RAS $+30 \%$ BB at a high temperature without burning the Bio-Binder. Therefore, the viscosity results for $90 \%$ RAS $+30 \%$ BB obtained at low temperature are extrapolated to high temperatures using this linear equation:

$$
Y=-25.879 X+6253.4
$$

Similarly, it is not possible to run the RV test on $90 \%$ RAS at low temperature, because $90 \%$ RAS is stiff at low temperature. Therefore, the viscosity results for $90 \%$ RAS obtained at high temperature are extrapolated to low temperatures using this linear equation:

$Y=-9.7533 X+1984.1$

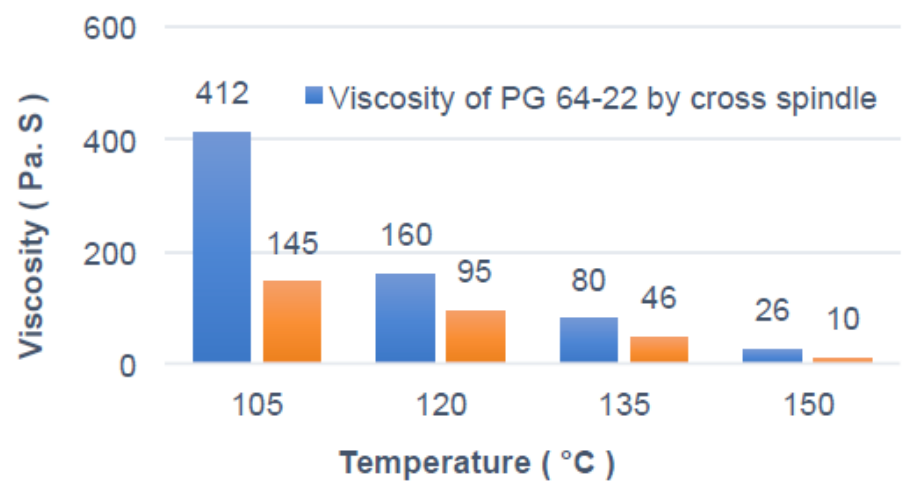

Fig. 2. The viscosity of neat binder measured using a cross spindle and a cylinder spindle

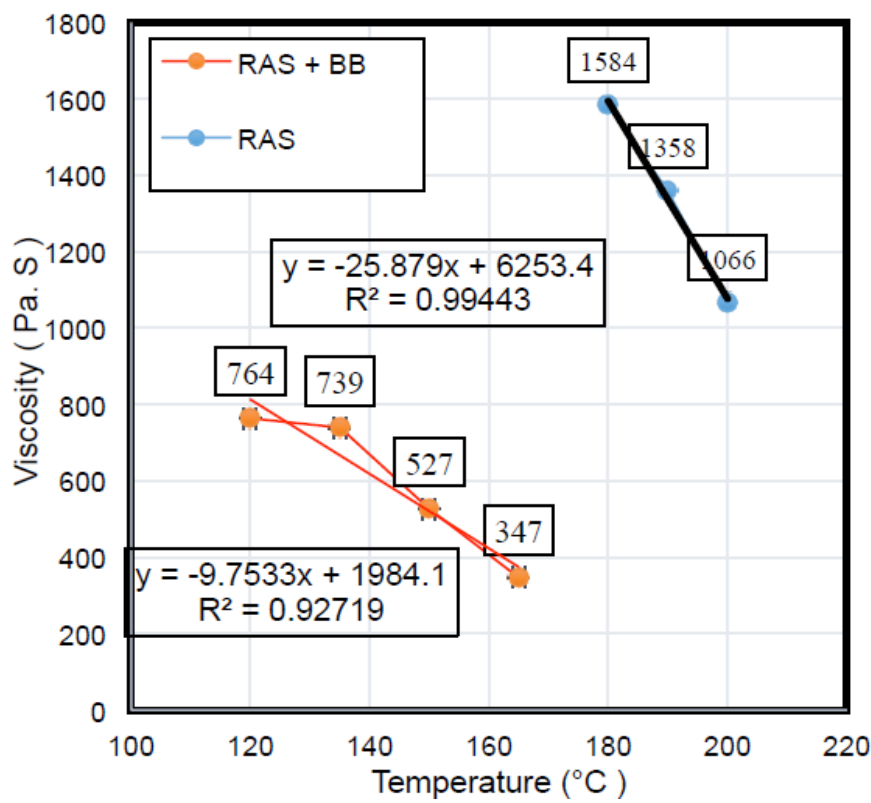

Fig. 3. Equations used to extrapolate the viscosities of $90 \%$ RAS and $90 \%$ RAS $+30 \%$ BB 


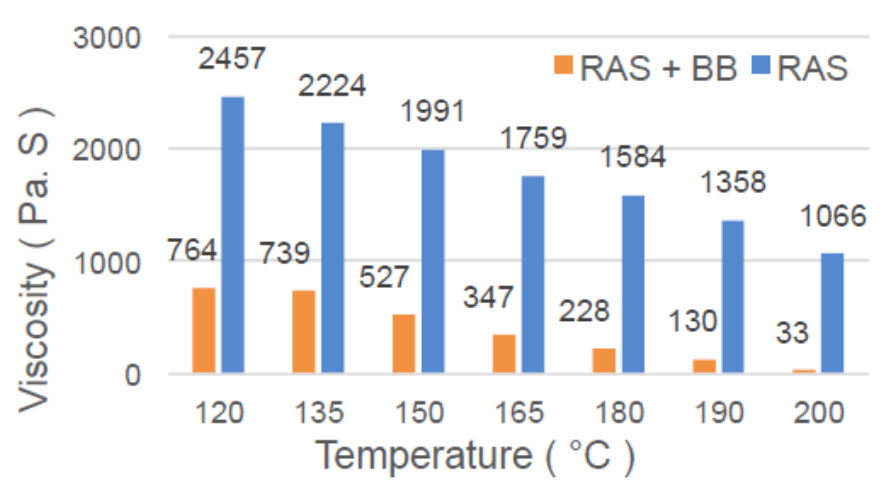

Fig. 4. The measured and extrapolated viscosities of $90 \%$ RAS and $90 \%$ RAS $+30 \%$ BB

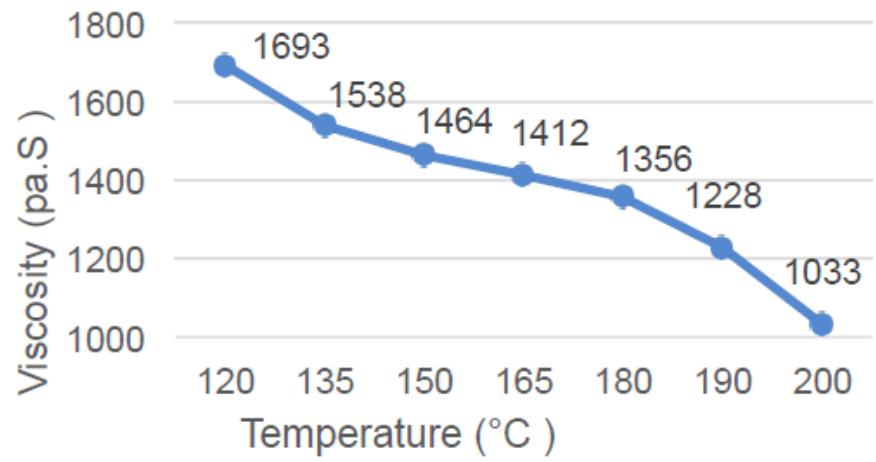

Fig. 5. The reduced viscosity after introducing $30 \%$ Bio-Binder to $90 \%$ RAS

Figure 4 shows the measured and extrapolated viscosities of $90 \%$ RAS and $90 \%$ RAS $+30 \%$ BB for the range of temperatures from 120 to $200^{\circ} \mathrm{C}$.

Figure 5 shows the reduced viscosity after the introduction of $30 \%$ Bio-Binder to $90 \%$ RAS. The iscosity result of $90 \%$ RAS $+30 \%$ BB (Bio-RAS) at $120,135,150,165,180,190$ and $200^{\circ} \mathrm{C}$ has been decreased by $68,66,73,80,85,90$ and $96 \%$ respectively.

\section{The Effect of Bio-Binder on Segregation in 90\% $R A S$}

Segregation is the most serious problem that can occur in asphalt concrete manufacture. It can occur in the design, mixture or in the pavement. Segregation is a frequently recurring problem that has caused concern specifically when adding RAS to the asphalt concrete. This study focuses on reducing segregation by using Bio-Binder. The Cigar Tube Test (CTT) is used to determine segregation in asphalt concrete, because one way to determine segregation is to measure the difference in viscosity of RAS and BioRAS. Figure 6 displays the viscosity of RAS after the CTT. The viscosity of the bottom was $80 \%$ higher than the top at $190^{\circ} \mathrm{C}, 74 \%$ at $200^{\circ} \mathrm{C}$ and $75 \%$ at $210^{\circ} \mathrm{C}$. The large differences between the viscosities of top and bottom show that 90\% RAS has high segregation. This could cause problems for asphalt mixing plants using this binder.

Figure 7 shows the viscosity of the top and bottom samples from a CTT after 30\% Bio-Binder was introduced to the $90 \%$ RAS. The viscosity of the bottom of Bio-RAS was $10 \%$ higher than the top at $120^{\circ} \mathrm{C}, 10 \%$ at $135^{\circ} \mathrm{C}, 11 \%$ at $150^{\circ} \mathrm{C}$ and $10 \%$ at $165^{\circ} \mathrm{C}$. The difference in viscosity between the top and bottom of RAS + BB became less which means the segregation reduced because of Bio-Binder. This could be because the Bio-Binder helped improve the interaction of the RAS particles and the asphalt binder.

\section{The Effect of Bio-Binder on the Complex Modulus} of $90 \% R A S$

As aforementioned, the complex shear modulus $\left(\mathrm{G}^{*}\right)$ was determined using the dynamic shear rheometer. $\left(G^{*}\right)$ is defined as the ratio of total shear stress to the total shear strain. Determining the complex shear modulus helps to determine the asphalt's total resistance to deformation.

Figure 8 shows the complex modulus of $90 \%$ RAS at different temperatures. As expected, the $\mathrm{G}^{*}$ of $90 \%$ RAS is too high due to the presence of oxidized bitumen from RAS. Therefore, the $90 \%$ RAS is expected to be brittle and if it were reused in asphalt concrete pavement, it would cause undesirable properties that are unacceptable in the manufacture of asphalt. 


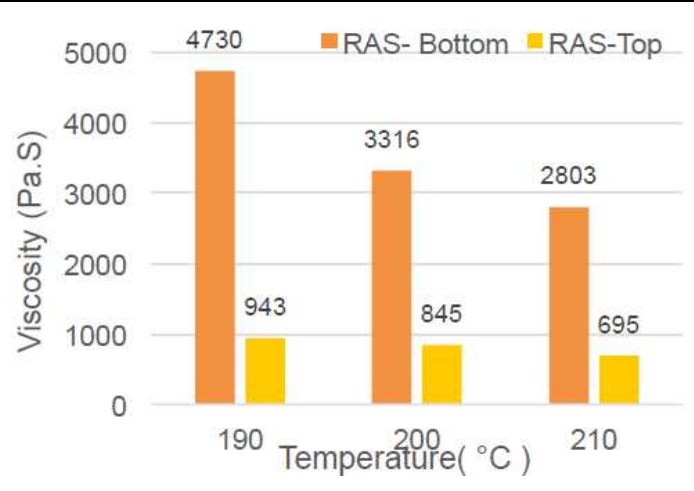

Fig. 6. Viscosity results showing the difference between bottom and top for RAS

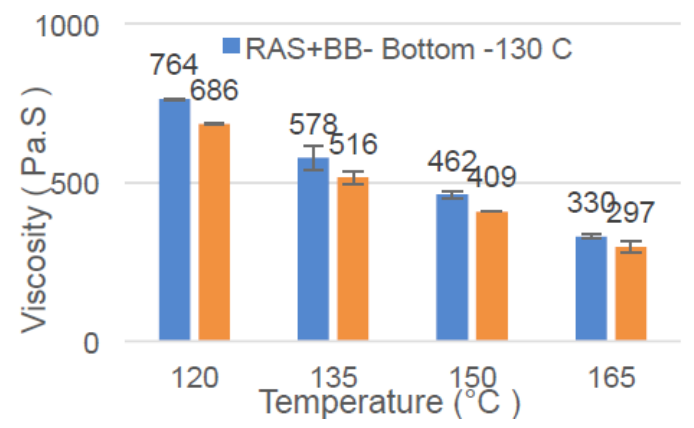

Fig. 7. The viscosity results of the CTT at $130^{\circ} \mathrm{C}$ for RAS $+\mathrm{BB}$

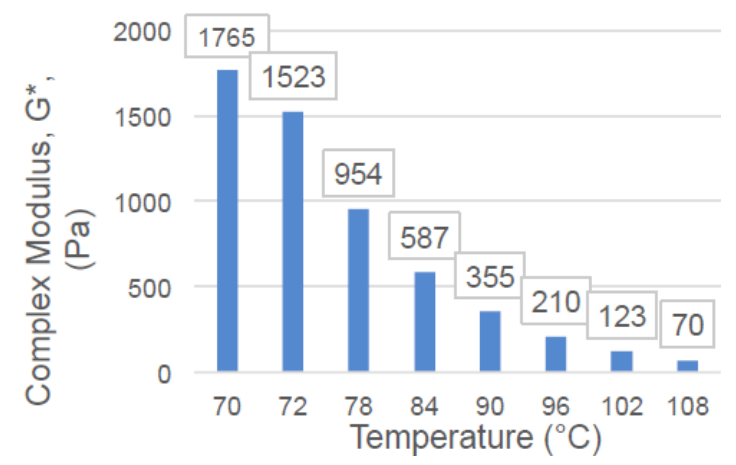

Fig. 8. The complex modulus $\left(\mathrm{G}^{*}\right)$ of RAS from 70 to $108^{\circ} \mathrm{C}$ at constant frequency $(10 \mathrm{rad} / \mathrm{sec})$

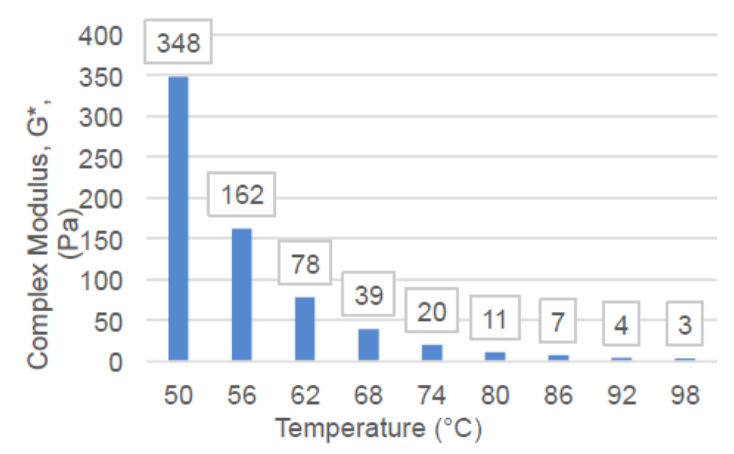

Fig. 9. The complex modulus $\left(\mathrm{G}^{*}\right)$ of $\mathrm{RAS}+\mathrm{BB}$ from $50^{\circ} \mathrm{C}$ to $98^{\circ} \mathrm{C}$ at constant frequency $(10 \mathrm{rad} / \mathrm{sec})$

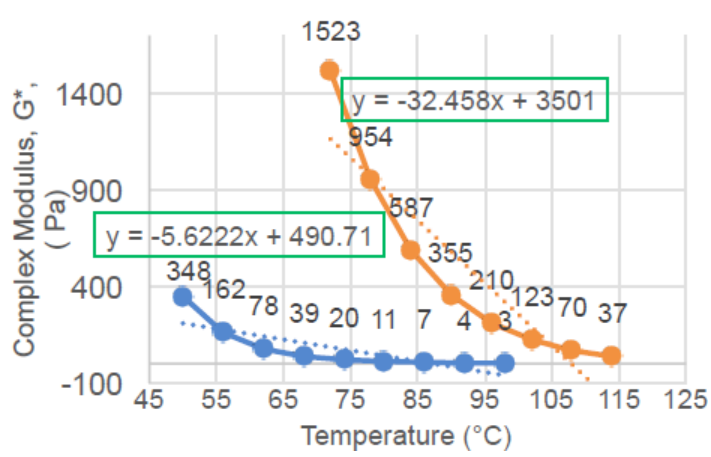

Fig. 10. The equations used to estimate the complex modulus of RAS at low temperatures (black) and RAS + BB at high temperatures (red)

Figure 9 shows the complex shear modulus of RAS + BB. The $\mathrm{G}^{*}$ of $90 \%$ RAS $+30 \%$ BB is lower than the $\mathrm{G}^{*}$ of $90 \%$ RAS. As expected, Bio-Binder helped reduce the complex modulus when introduced to the $90 \%$ RAS sample. The introduction of Bio-Binder caused a reduction in the viscosity of RAS, which could be due to an increase in the interaction between the particles of RAS and the particles of Bio-Binder. Therefore, the biomodified recycled asphalt shingles (Bio-RAS) became softer and more elastic. In addition, the Bio-RAS became more flexible and less susceptible to cracking. Figure 10 shows the equations used to estimate the complex modulus of both the RAS and RAS + BB. This linear equation is used to extrapolate the RAS complex modulus to low temperatures:

$Y=-32.458 X+3501$

The linear Equation 4 is used to extrapolate the $\mathrm{G}^{*}$ for RAS + BB at low temperatures to get the complex modulus of RAS $+\mathrm{BB}$ at higher temperatures:

$Y=-5.6222 X+490.71(5)$

Figure 11 shows the influence of Bio-Binder on the complex shear modulus. After estimating the complex modulus, it was found that $\mathrm{G}^{*}$ decreased by $81,90,94$, $96,98,98,99,99,99$ and $99 \%$ at 50, 56, 62, 68, 74, 80, $86,92,98$ and $104^{\circ} \mathrm{C}$, respectively.

Adding Bio-Binder to the mixture causes the value of $\mathrm{G}^{*}$ to decrease may be due to a resulting increase in the interaction between the ingredients of the mixture. Figure 12 shows the reduction in the complex modulus after introducing Bio-Binder to RAS. The results show the delta reduction dropped from $1529 \mathrm{~Pa}$ at $50^{\circ} \mathrm{C}$ to $99 \mathrm{~Pa}$ at $108^{\circ} \mathrm{C}$ at constant frequency $10(\mathrm{rad} / \mathrm{s})$. The above results indicated an improvement in the characteristics and properties of RAS after the introduction of Biobinder. The new product Bio-RAS is expected to have less deformation and less fatigue cracking but less resistance to rutting. 


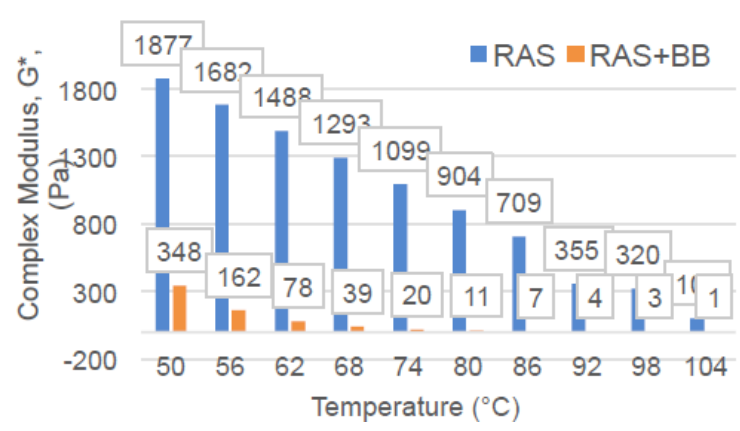

Fig. 11. Complex modulus data and extrapolation of RAS and RAS + BB from 50 to $104^{\circ} \mathrm{C}$

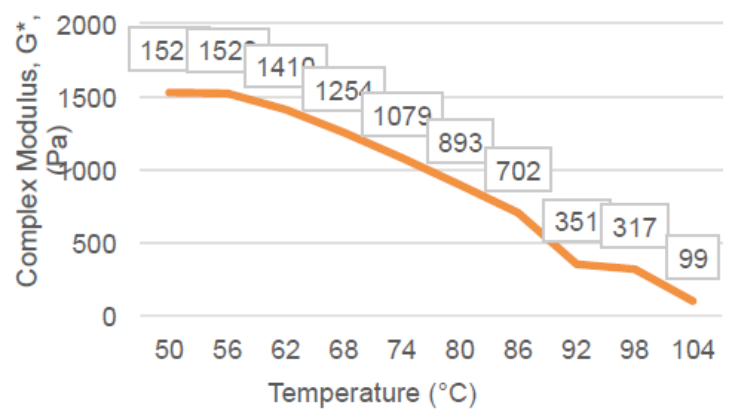

Fig. 12. The delta $\mathrm{G}^{*}$ of RAS and RAS $+\mathrm{BB}$ at constant frequency $(10 \mathrm{rad} / \mathrm{s})$ for temperature range 50 to $104^{\circ} \mathrm{C}$

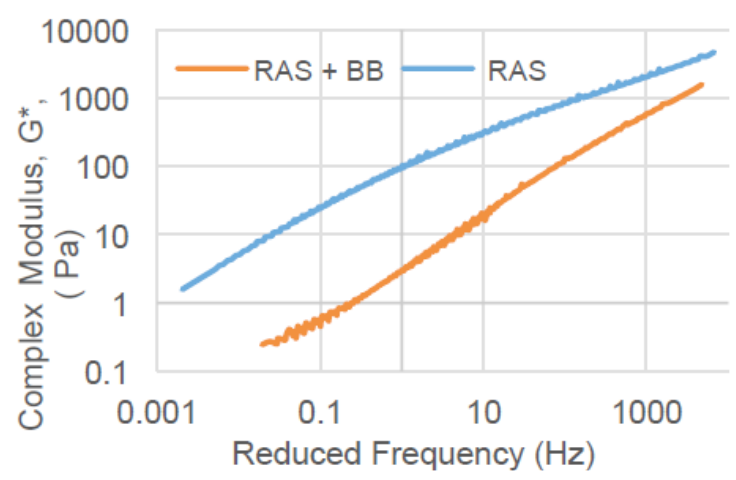

Fig. 13. Complex Modulus of RAS and RAS + BB

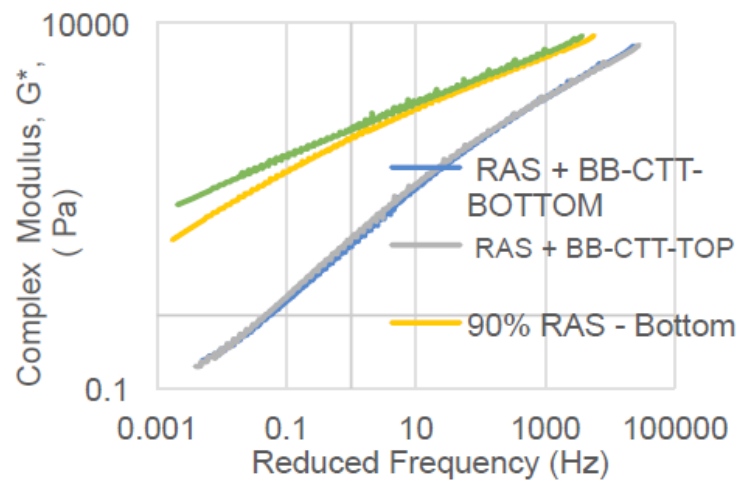

Fig. 14. The $\mathrm{G}^{*}$ difference for RAS (top, bottom) and RAS + BB (top, bottom) after CTT
Figures 13 and 14 show the master curves for the complex modulus of RAS and $\mathrm{RAS}+\mathrm{BB}$ at 31 frequencies ranging from 0.1 to $100 \mathrm{rad} / \mathrm{s}$ at 68 to $114^{\circ} \mathrm{C}$ for RAS and 50 to $98^{\circ} \mathrm{C}$ for RAS + BB. Figure 13 compares the complex modulus of RAS and RAS + BB. It is clear the complex modulus of RAS $+\mathrm{BB}$ is much lower than the complex modulus of RAS alone indicating that Bio-Binder causes a large reduction in $\mathrm{G}^{*}$. At low reduced frequencies, which correlate with low-intermediate temperatures, the complex modulus of RAS is notably higher than that of RAS $+\mathrm{BB}$. This indicates that $\mathrm{BB}$ can soften the RAS samples in this range. The difference between RAS and RAS + BB decreases as the reduced frequency increases. This decrease in difference could be because of the filler effect of the RAS particles.

Figure 14 illustrates the difference between the complex modulus of RAS and RAS $+\mathrm{BB}$ after a cigar tube test. It is clear from the master curves that the difference between top and bottom's complex modulus of the $90 \%$ RAS is greater than the corresponding difference of RAS + BB. Introducing Bio-Binder to $90 \%$ RAS reduced the delta complex modulus, which means the segregation relates to low-intermediate temperatures. In addition, the difference between the complex modulus of the bottom and top for $90 \%$ RAS increased when the temperature increased. This behaviour is not noticeable with RAS $+\mathrm{BB}$, because there is less segregation because of Bio-Binder.

\section{Discussion}

\section{Effect of BB on the Relaxation Time of $90 \%$ RAS}

Relaxation Time (RT) is defined as the time required for the stress to drop from an initial value to 0.368 or e- 1 of the initial value $(\mathrm{e}=2.718)$. It is the time required for unstable materials to return to equilibrium. In this study, a DSR was used to measure the relaxation time. It is clear the relaxation time of $90 \%$ RAS is much higher specifically at low temperature and that because the $90 \%$ RAS is stiff materials, therefore, stress takes longer time to dissipate through RAS after a load is applied. Figure 15 shows the RT of RAS is $2.982 \mathrm{sec}$ at $60^{\circ} \mathrm{C}, 1.235 \mathrm{sec}$ at $70^{\circ} \mathrm{C}, 0.806 \mathrm{sec}$ at $80^{\circ} \mathrm{C}$ and $0.571 \mathrm{sec}$ at $90^{\circ} \mathrm{C}$. The RT of $\mathrm{RAS}+\mathrm{BB}$ is much lower than the RT of $90 \%$ RAS, due to the fact that the addition of Bio-Binder to the RAS may contributed to the change in the characteristics of the mixture: Softer, more elastic and lower viscosity.

Figure 15 shows the RT of $90 \%$ RAS $+30 \%$ BB is $0.268 \mathrm{sec}$ at $60^{\circ} \mathrm{C}, 0.152 \mathrm{sec}$ at $70^{\circ} \mathrm{C}, 0.081 \mathrm{sec}$ at $80^{\circ} \mathrm{C}$ and $0.059 \mathrm{sec}$ at $90^{\circ} \mathrm{C}$. Figure 16 clearly shows that the introduction of Bio-Binder to RAS caused a reduction in the Relaxation Time (RT). The relaxation time at $60^{\circ} \mathrm{C}$ dropped from $2.288 \mathrm{sec}$ for RAS to $0.264 \mathrm{sec}$ for RAS + $\mathrm{BB}$, which means the relaxation time dropped $91 \%$ after introducing Bio-Binder to RAS. 


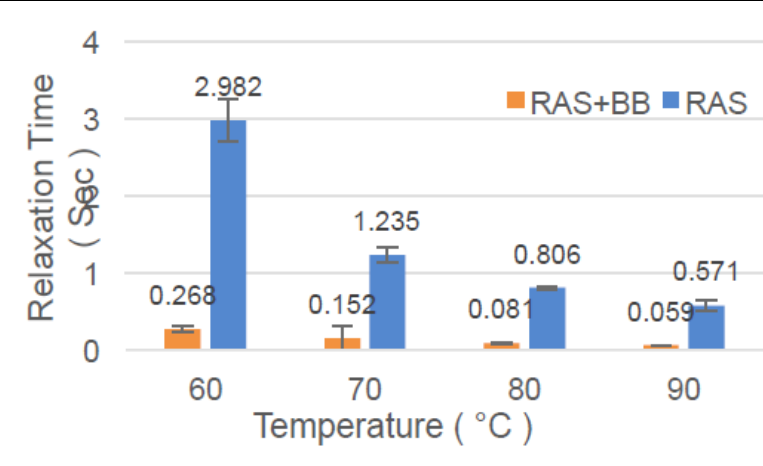

Fig. 15. The relaxation times of RAS and RAS + BB

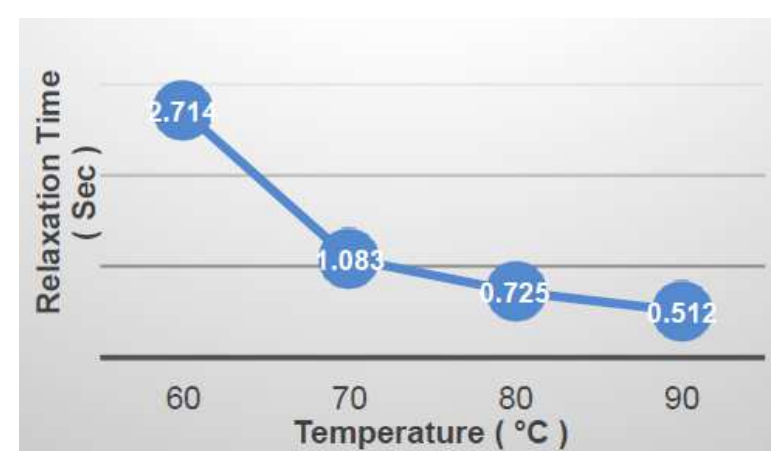

Fig. 16. The reduction in relaxation time (sec) after introducing Bio-Binder to RAS

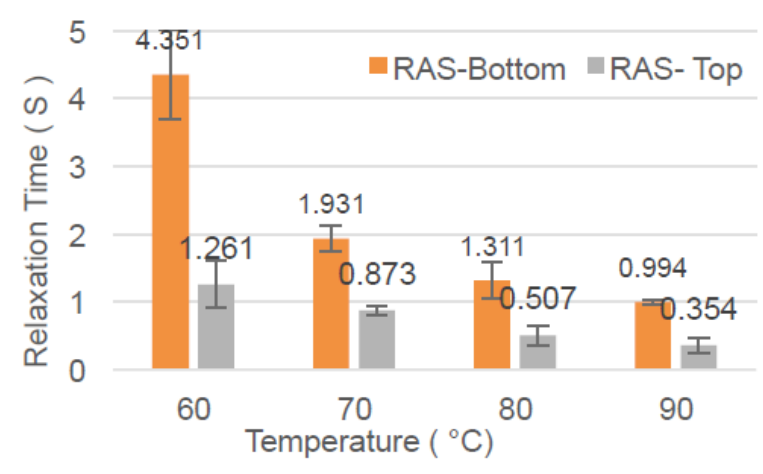

Fig. 17. Relaxation times of the bottom and top of RAS

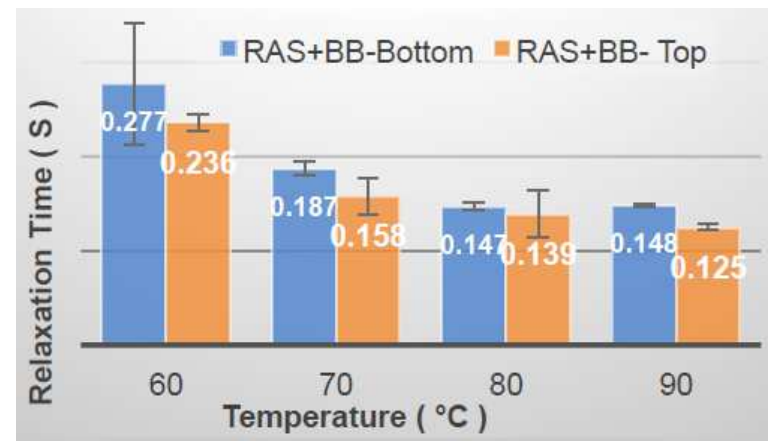

Fig. 18. The relaxation times of the bottom and top of RAS + BB
Also, the RT dropped $87 \%$ at $70^{\circ} \mathrm{C}, 89 \%$ at $80^{\circ} \mathrm{C}$ and $89 \%$ at $90^{\circ} \mathrm{C}$. All these results show that the stress recovery improves over time after introducing BioBinder to RAS.

\section{Relationship between Relaxation Time and Segregation}

As aforementioned, the Cigar Tube Test (CTT) was used to study the effect of segregation on the relaxation time of RAS (bottom and top) and RAS + BB (bottom and top). The segregation was determined by measuring the difference in relaxation time between the bottom and top of RAS and the difference in relaxation time between the bottom and top of RAS + BB. Figure 17 shows that the RT of RAS-Bottom is much higher than the RT of RAS-Top; it is higher by $71 \%$ at $60^{\circ} \mathrm{C}, 54 \%$ at $70^{\circ} \mathrm{C}, 61 \%$ at $80^{\circ} \mathrm{C}$ and $64 \%$ at $90^{\circ} \mathrm{C}$, respectively.

These results indicate that the segregation in the RAS specimen in a CTT was high. Therefore, stress recovery takes longer to dissipate through RAS-Bottom than through RAS-Top after a load is applied.

Figure 18 shows the RT values of the top and bottom portions of RAS + BB. As shown, it is much less than the corresponding values of the RAS. The relaxation time of RAS + BB- Bottom was higher than the relaxation time of RAS + BB- Top by $14,15,5$ and $15 \%$ at $60,70,80$ and $90^{\circ} \mathrm{C}$, respectively. These results show that there is very little difference in relaxation time between the bottom and top of RAS + BB (Bio-RAS). The small difference in relaxation time between the top and bottom of Bio-RAS means there is very little segregation in the RAS + BB specimen in a CTT. From these results, the segregation in Bio-RAS is less than the segregation in RAS and these improvements in the rheological properties of RAS are because of BioBinder. The Bio-binder helped to increase the interaction between all particles of the specimen. Therefore, the stress takes less time to dissipate through Bio-RAS after a load is applied.

\section{Conclusion}

Use of recycled asphalt shingles in the asphalt pavement could provide an economical benefit to asphalt industry. However, one of the major engineering problems of adding recycled asphalt shingles to HMA is the resulted changes in the rheological behavior of the final AC product. There are two reasons behind this behavior change: The bitumen of RAS is undergoing a stiffening process during production and oxidation due to the years of service. Due to the stiffening effect of adding RAS, blending binder from recycled materials to asphalt binder may improve both the high and low temperatures grade's performance of the final blend at. 
The increase in the high-temperature grade could reduce deformation in the permanent. On the other hand, an increase in the low temperature end may cause low temperature cracking. Therefore, the best thing to do to fix the behavior change in the asphalt concrete is to rejuvenate the bitumen extracted from recycle asphalt shingles to get both economical and performance benefit from use RAS in the asphalt manufacture.

In this study, Bio-Binder (from swine manure) was introduced to RAS. The results showed that BB decreased both the viscosity and stiffness of Biomodified asphalt. The following conclusions were drawn:

- Use of recycled asphalt shingles in AC could increase the viscosity and stiffness of the modified AC

- The Bio-Binder used in this study helped to rejuvenate the RAS and led to improvement in the rheological properties. Results show that adding BioBinder to RAS leads to reduce the viscosity, reduce the modulus shear complex $\mathrm{G}^{*}$, reduce the relaxation time RT and reduce the segregation of RAS:

- $\quad$ The viscosity of the bio-modified asphalt (Bio-RAS) is lower than that of the $90 \%$ RAS. Compared to the viscosity of RAS, the viscosity result of $90 \%$ RAS $+30 \%$ BB (Bio-RAS) at 120, 135, 150, 165, 180, 190 and $200^{\circ} \mathrm{C}$ has been decreased by $68,66,73$, $80,85,90$ and $96 \%$ respectively. It was found that the viscosity of Bio-RAS at $159.59^{\circ} \mathrm{C}$ is equal to the viscosity of neat asphalt $\mathrm{PG} 64-22$ at $105^{\circ} \mathrm{C}$, which means that Bio-Binder reduced the viscosity of RAS, therefore $90 \%$ RAS $+30 \%$ BB was softer than RAS. That could be due to an increase in homogeneity between the bitumen and Bio-Binder, because of an increase in the bond between them

- The complex shear modulus is much higher in RAS than in RAS + BB. Compared to the $\left(\mathrm{G}^{*}\right)$ of RAS it was found that $\mathrm{G}^{*}$ of RAS + BB decreased by 81 , $90,94,96,98,98,99,99,99$ and $99 \%$ at $50,56,62$, $68,74,80,86,92,98$ and $104^{\circ} \mathrm{C}$, respectively. The decrease of $\mathrm{G}^{*}$ when adding Bio-Binder to the mixture may be due to the increase in the interaction between the ingredients of the mixture. That means there is a decrease in the stiffness of RAS when BB is introduced; the Bio-RAS becomes softer.

- The RT of $90 \% \mathrm{RAS}+30 \% \mathrm{BB}$ is $0.268 \mathrm{sec}$ at $60^{\circ} \mathrm{C}$, $0.152 \mathrm{sec}$ at $70^{\circ} \mathrm{C}$ and $0.081 \mathrm{sec}$ at $80^{\circ} \mathrm{C}$ and the RT of $90 \%$ RAS is $2.982 \mathrm{sec}$ at $60^{\circ} \mathrm{C}, 1.235 \mathrm{sec}$ at $70^{\circ} \mathrm{C}$ and $0.806 \mathrm{sec}$ at $80^{\circ} \mathrm{C}$. The RT of RAS + BB is much lower than the relaxation time of RAS; the RT for RAS+BB was a decrease of $91 \%$ at $60^{\circ} \mathrm{C}, 87 \%$ at $70^{\circ} \mathrm{C}$ and $89 \%$ at $80^{\circ} \mathrm{C}$. All these improvements are due the effect of Bio-Binder on $90 \%$ RAS, as mentioned before
- The RT of RAS-Bottom is much higher than the RT of RAS-Top; it is higher by $71 \%$ at $60^{\circ} \mathrm{C}, 54 \%$ at $70^{\circ} \mathrm{C}, 61 \%$ at $80^{\circ} \mathrm{C}$ and $64 \%$ at $90^{\circ} \mathrm{C}$, respectively. These results indicate that the segregation in the RAS specimen in a CTT was high. Therefore, stress recovery takes longer to dissipate through RASBottom than through RAS-Top after a load is applied

- The relaxation time of RAS + BB- Bottom was higher than the relaxation time of RAS + BB- Top by $14,15,5$ and $15 \%$ at $60,70,80$ and $90^{\circ} \mathrm{C}$, respectively. The small difference in relaxation time between the top and bottom of Bio-RAS means there is very little segregation in the RAS $+\mathrm{BB}$ specimen in a CTT. From these results, the segregation in Bio-RAS is less than the segregation in RAS and these improvements in the rheological properties of RAS are because of Bio-Binder. The Bio-binder helped to increase the interaction between all particles of the specimen. Therefore, the stress takes less time to dissipate through Bio-RAS after a load is applied

\section{Acknowledgement}

This research is sponsored by NSF (Award No: 1640517) and NC A\&T State University. The content of this paper reflects the view of the authors, who are responsible for the facts and the accuracy of the data presented. The authors would like to acknowledge the support and assistance of Mr. Oldham with SIM lab at NC A\&T.

\section{Author's Contributions}

Mohammed Jawad: Performed laboratory experiments, participated in all data-analysis and conducted data analysis of the research.

Elham H. Fini: Participated in all laboratory plants and experiments, data-analysis and conducted data analysis of the research.

Taher M. Abu-Lebdeh: Participated in all Experimental plan, review data-analysis and contributed to the writing of the manuscript.

\section{Ethics}

No part of this article may be reproduced without written permission from the publisher or authors.

\section{References}

AASHTO T 316, 2012. AASHTO T 316, determining the rheological properties of asphalt binder using a dynamic shear Rheometer. Washington, DC.

ASTM D4402/D4402M-15 Standard Test Method for Viscosity Determination of Asphalt at Elevated Temperatures Using a Rotational Viscometer. 
ASTM D7173-14 Standard Practice for Determining the Separation Tendency of Polymer from Polymer Modified Asphalt.

ASTM D7552-09, 2014. Standard test method for determining the complex shear modulus $\left(\mathrm{G}^{*}\right)$ of bituminous mixtures using dynamic shear Rheometer. ASTM International, West Conshohocken, PA.

Elseifi, M.A., S. Salari, L.N. Mohammad, M. Hassan and W.H. Daly et al., 2012. New approach to recycling asphalt shingles in hotmix asphalt. J. Mater. Civil Eng., 24: 1403-1411.

Fini, E.H., E. Kalberer and A. Shahbazi, 2011. Biobinder from swine manure: Sustainable alternative for asphalt binder. Proceedings of the TRB 90th Annual Meeting Compendium of Papers, (MCP' 11), DVD, Transportation Research Board of the National Academies, Washington, D.C., pp: 34-53.
Nam, B., H. Maherinia and A.H. Behzadan, 2014. Mechanical characterization of asphalt tear-off roofing shingles in Hot Mix Asphalt. Construct. Build. Mater., 50: 308-316.

Oldham, D.J., E.H. Fini and E. Chailleux, 2015. Application of a bio-binder as a rejuvenator for wet processed asphalt shingles in pavement construction. Constr. Build. Mater., 86: 75-84.

Oldham, D., E.H. Fini and T. Abu-Lebdeh, 2014. Investigating the rejuvenating effect of biobinder on recycled asphalt shingles. Proceedings of the Transportation Research Board 93rd Annual Meeting.

Soleimanbeigi, A., T. Edil and J. Tinjum, 2013. Effect of temperature on shear strength of recycled asphalt shingles. J. Transport. Res. Board, 2349: 55-62. 